\title{
Soil deformation model analysis in the processing of the geotechnical monitoring results.
}

\author{
VladimirSyasko ${ }^{1}$, Aleksander Shikhov ${ }^{2}$. \\ ${ }^{1}$ Saint Petersburg Mining University, Department of Metrology, Instrumentation and Quality \\ Management, KONSTANTA, LLC, Saint Petersburg, Russia. \\ ${ }^{2}$ Saint Petersburg Mining University, Department of Metrology, Instrumentation and Quality \\ Management, Saint Petersburg, Russia.
}

\begin{abstract}
Much of the territory of the Russian Federation is located in the permafrost soil area. The developed hydrocarbon deposits make a significant contribution to the budget of the Russian Federation. Therefore, ensuring trouble-free operation of engineering structures and these fields is the most crucial task. Frozen soil deformation leads to violations in the operation of structures, which entail economic harm and significant environmental problems. This article provides a brief overview of the leading causes of deformations of engineering structures built on permafrost soils. The methods currently used to stabilize the frozen soil deformation are considered, and the directions for solving this problem are proposed.
\end{abstract}

\section{Introduction}

More than $65 \%$ of the territory of the Russian Federation is located in the permafrost zone. The exploitation of existing and exploration of new hydrocarbon deposits is the most critical direction of increasing the raw material base of the Russian Federation. The developed territories are characterized by a continuous distribution of permafrost; the primary composing rocks are dispersed and clay soils. Such soils are characterized by high load-bearing capacity and lack of compressibility in the solid-frozen state, but the soils' deformation properties deteriorate significantly during the transition to the plastic-frozen state. Frozen soil is a fourcomponent system, the distinctive feature of which is ice, which provides a connection between the mineral components of the soil and largely characterizes the strength and deformation properties of frozen soils.

A few works are devoted to permafrost soil deformations. Due to the significant total length of the oil and gas pipeline routes and the serious industry-related danger of these objects, the bulk of the work is devoted to their deformation [1-3]. Also, the research of many authors is devoted to the deformation of highways [4,5].

Particular attention should be paid to the works devoted to the methods of stabilizing the base deformations. In general, all research in this area can be divided into research on the development of foundation structures that counteract soil deformations [6,7] and the development of methods for stabilizing the temperature regime of soils $[8,9]$. 
In the construction of buildings and structures, in areas of permafrost distribution, on the territory of the Russian Federation, the main principle is the first construction principle [10], that is, with the preservation of the frozen state of the soil both for construction and operation periods. The construction of permafrost soils entails a change in the soil temperature regime, leading to their thawing. According to [10], the design of a structure must include a thermal calculation of the structure's foundation, taking into account the effect of heat exchange between the structure and the ground base. As practice shows, the actual changes in the soil deformation properties, and their values obtained from thermal engineering calculations, often do not coincide. According to many researchers, the thermal engineering forecast of the impact of the structure on the frozen ground is complicated by the fact that during the operation of the structure, the physical and deformation properties of the soil can change, especially during the activation of geocryological processes [11].

The most crucial factor in the stability of permafrost soils is weather conditions. The influence of various climatic factors on the permafrost distribution is studied in $[12,13]$. Activation of geocryological processes leads to the formation of frost mounds, cryokarsts, and frozen soil degradation.

Climate changes significantly contribute to the change in the base operational properties, but it is premature to blame them alone for the increasing frequency of accidents. In addition to natural factors, the current situation may indicate the unsuitability of the currently used methods and means of forecasting and monitoring the permafrost soil state.

In the authors' opinion, a productive method of combating base deformations can identify at an early stage. Conducting geotechnical monitoring will allow responding promptly to changes in the soil mass and stabilizing the state. Various methods and techniques of geotechnical monitoring are described in [14-17]. None of the presented methods is based on the determination and monitoring of soils' deformation properties, although deformation calculation is mandatory when designing the base.

In this paper, the analysis of the existing deformation theories of soils is carried out for further application in the processing of geotechnical monitoring results.

\section{METHODOLOGY}

Various deformation theories are used to model the behavior of soils.

The basis of the deformation plasticity theory is the expression [18]:

$$
[\sigma]=[D]\{\varepsilon\}
$$

where $[D]$ - elasticity matrix; $[\sigma]$ - stresses; $\{\varepsilon\}$-deformations;

The deformation modulus for a unit deformation is determined to account for the nonlinear relationship of stresses and deformations, Figure 1, therefore, to apply this theory, it is necessary to establish:

where $E$ - soil deformation modulus.

$$
E=f(\sigma)
$$




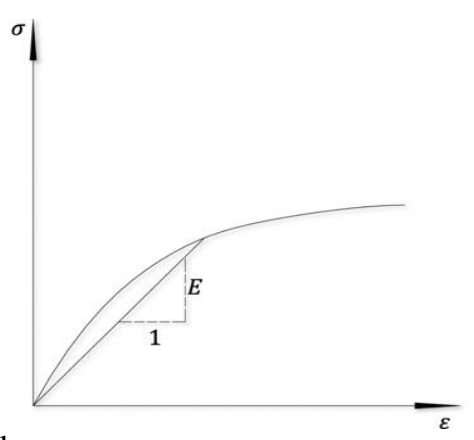

Fig. 1. Deformation plasticity theory.

When applying the elastic-plastic theory of soil deformation, the nonlinear relationship between stresses and deformations is described by the introduction of limiting yield surfaces Figure 2 .

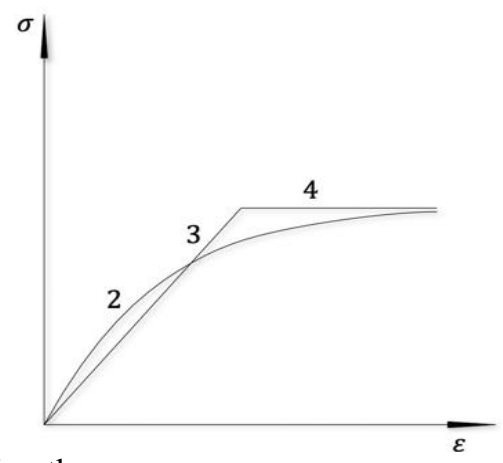

Fig. 2. Elastic-plastic deformation theory.

2 - actual behavior of soils; 3 - linear section of soil deformation; 4 - limit surface;

A significant number of equations are known to describe the limit surface, and the Coulomb, Tresk, and Von Mises criteria are the most widely used [18]:

$$
\begin{gathered}
F=\tau-c-\sigma \operatorname{tg} \varphi+f(k)=0, \\
F=\tau_{0}-c+f(k)=0, \\
F=\tau-c+f(k)=0 ;
\end{gathered}
$$

where $\tau$ - shear stresses; $c$ - coupling; $\varphi$ - angle of internal friction.

As shown in the expressions shown above, the elastic-plastic theory is described by strength properties, in contrast to the plastic theory described by the soil deformation characteristics.

In frozen soils, flow properties are clearly expressed - stress relaxation and creep. Viscoelastic and viscoplastic elements are used to model the rheological properties of soils Figure 3. 


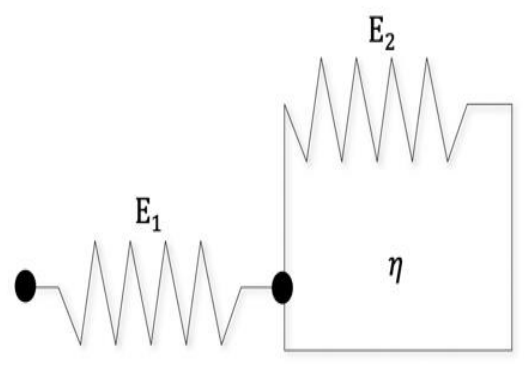

Fig. 3. Viscoelastic element.

In this case, the stresses and deformations are related as follows:

$$
\epsilon=\sigma\left(\frac{1}{E_{1}}+\frac{1}{E_{2}}\right)\left(1-e^{-\frac{t E_{2}}{\eta}}\right) ;
$$

where $\epsilon$ - deformation rate; $\eta$ - viscosity ratio;

As mentioned above, frozen soils are characterized by rheological properties. When predicting the stress-strain state of frozen soils, it is undoubtedly necessary to take this fact into account. However, as noted above, the results of assessing the soil deformation properties according to the methods developed earlier for predicting the stress-strain state do not agree with field observations. Therefore, the question arises about the feasibility of developing a methodology for predicting the stress-strain state of soils. In the authors' opinion, an urgent task is to develop an assessment methodology for the soil states based on the indicators of deformation properties determined at a given time. In this case, there is no need to take into account the rheological properties of the soil.

The engineering and geological methods used to determine these models' input parameters cannot be used for geotechnical monitoring. A promising direction is acoustic monitoring, so applying these deformation theories will be considered regarding the possibility of determining the input parameters by the acoustic monitoring.

The kinematic characteristics of the elastic wave are related to the soil deformation properties:

$$
E=V_{P}^{2} \cdot \rho \cdot \frac{(1+\mu)(1-2 \mu)}{1-\mu}
$$

where $V_{p}$ - propagation rate of the longitudinal wave; $\mu$ - the Poisson's ratio; $\rho$ - soil density;

Based on this, it can be concluded that it is optimal to use the deformation plasticity theory when conducting geotechnical monitoring with acoustic monitoring. However, it should be remembered that the results of acoustic studies determine the dynamic modulus of soil deformation, for which the following is always true:

$$
E>E_{\text {com }}
$$

where $E_{c o m}$ - the total soil deformation modulus determined by the results of engineering and geological studies. 


\section{CONCLUSION}

According to the first construction principle, climate changes occurring on the Russian Federation's territory threaten the operation of engineering structures in the areas of permafrost distribution. Timely detection of the degradation of permafrost soils and applying stabilization methods for the soil will prevent an emergency. In the author's opinion, a method that directly measures the soil deformation properties is required. A promising direction is acoustic monitoring. However, despite the widespread use of this method and its application in studying the physical and mechanical properties of soils [19-21], it is necessary to solve the transition from the dynamic soil deformation modulus to the general deformation modulus.

\section{References}

1. N. A. Kolokolov, N. A. Harris, On the choice of a method for laying pipelines in permafrost areas, Transport and storage of petroleum products and Hydrocarbons, 1 (2013).

2. N. H. Gabdrakhmanov, Sh. G. Mingulov, V. A. Strizhnev, R. D. Karimov, Diagnostics of field pipelines as a means of improving the reliability of pipeline systems, Journal of Mining Institute, 164, 95 (2005).

3. A. N. Lyubchik, E. I. Krapivskii, O. M. Bol'shunova, Prediction of the technical status of pipeline based on analysis, Journal of Mining Institute, 192, 153 (2011).

4. E. Volkova, I. Solonenko, The causes of road deformations and measures to reduce their intensity with a high-temperature type of permafrost in the foundations of the roadbed on the example of the construction of the Amur highway "Chita-Khabarovsk", Izvestiya Vuzov. Investment. Construction. Real Estate, 2 (13) (2015).

5. E. A. Budrin, A. M. Zavyalov, M. A. Zavyalov, Forecasting of thermal (thermal) stability of the foundation of the roadbed, Bulletin of SibADI, 2 (24) (2011).

6. N. Yu. Botvineva, I. S. Burlakova, O. G. Fomenko, Foundations on structurally unstable soils, Modern science and innovations, 2 (14), 133-139 (2016).

7. E. V. Ibragimov, Ya. A. Kronik, Optimization of the device of bases and foundations in the cryolithozone (on the example of a vertical steel tank RVS-20000 $\mathrm{m}^{3}$ ), Geotechnika, 10, 52-61 (2018).

8. G. V. Koloskov, E. V. Ibragimov, R. G. Gamzaev, On the issue of choosing optimal systems for thermal stabilization of soils during construction in the cryolithozone, Geotechnika, 6, 4-11 (2015).

9. V. A. Gorkov, A. N. Korkishko, A.V. Nabokov, T. V. Krizhanivskaya, Yu. V. Ogorodnova, Stabilization of soils by the method of "cold recycling" in the conditions of permafrost soils for the development of oil and gas fields, Fundamental Research, 7, 20-24 (2017).

10. SP 25.13330.2012 Foundations and foundations on permafrost soils. Moscow: N. M. Gersevanov Research, Design and Survey and Design and Technological Institute of Foundations and Underground Structures, (2013).

11. G. S. Sannikov Changes in morphometric parameters of thermokarst lakes of the Western Yamal as an indicator of the dynamics of the geological environment and its reaction to man-made impacts (on the example of the Bovanenkovskoye field), (Abstract of the dissertation of the Candidate of Geological and Mineralogical Sciences : 25.00.08 / Sannikov Georgy Sergeevich; [Place of defense: Institute of Cryosphere of the Earth SB RAS]. Tyumen, 2016). 
12. A. Desyatkin, P. Fedorov, N. Filippov, R. Desyatkin, Climate Change and Its Influence on the Active Layer Depth in Central Yakutia. Land, 10, 3 (2021).

13. A. Desyatkin, F. Takakai, M. Nikolaeva, Landscape Microzones within Thermokarst Depressions of Central Yakutia under Present Climatic Conditions. Geosciences, 8, 439 (2018).

14. F. Cigna, V.J. Banks, A.W. Donald, S. Donohue, C. Graham, D. Hughes, J.M. McKinley, K. Parker, Mapping Ground Instability in Areas of Geotechnical Infrastructure Using Satellite InSAR and Small UAV Surveying: A Case Study in Northern Ireland. Geosciences, 7, 51 (2017).

15. P. Konstantinov, M. Zhelezniak, N. Basharin, I. Misailov, V. Andreeva, Establishment of Permafrost Thermal Monitoring Sites in East Siberia. Land, 9, 476 (2020).

16. A. I. Potapov, A. I. Shikhov, E. N. Dunaeva, Geotechnical monitoring of frozen soils: problems and possible solutions, IOP Conf. Ser.: Mater. Sci. Eng., 1064, 012038 (2021).

17. A. P. Popov Geotechnical monitoring in cryolite zone. Ecological or industrial safety, Journal of Mining Institute, 188, 167 (2010).

18. A. B. Fadeev, The Finite Element method, (Moscow: Nedra 1987).

19. V. Izotova, D. Petrov, K. Pankratova, G. Pospehov, Research of acousticcharacteristics and physical and mechanicalproperties of quaternarysoils, Engineering and Mining Geophysics (2020).

20. N. V. Babyr, A. I. Korolev, T. V. Neupokoeva, Enhancement of powered cleaning equipment with the view of mining and geological conditions, IOP: Earth and Environmental Science, 194 (2018).

21. J.-L. Mari, G. Porel, F. Delay, Contribution of Full Wave Acoustic Logging to the Detection and Prediction of Karstic Bodies, Water,12, 948 (2020). 